\title{
MicroFEWs: A Food-Energy-Water Systems Approach to Renewable Energy Decisions in Islanded Microgrid Communities in Rural Alaska
}

\author{
Erin Whitney,,2,* William E. Schnabel, ${ }^{2}$ Srijan Aggarwal, ${ }^{2,3}$ Daisy Huang, ${ }^{1,2,4}$ Richard W. Wies, Jr., ${ }^{1,2,5}$ \\ Justus Karenzi, ${ }^{5}$ Henry P. Huntington, ${ }^{6}$ Jennifer I. Schmidt, ${ }^{7}$ and Aaron D. Dotson ${ }^{8}$ \\ ${ }^{1}$ Alaska Center for Energy and Power, University of Alaska Fairbanks, Fairbanks, Alaska. \\ ${ }^{2}$ Institute of Northern Engineering, University of Alaska Fairbanks, Fairbanks, Alaska. \\ ${ }^{3}$ Department of Civil and Environmental Engineering, University of Alaska Fairbanks, Fairbanks, Alaska. \\ ${ }^{4}$ Department of Mechanical Engineering, University of Alaska Fairbanks, Fairbanks, Alaska. \\ ${ }^{5}$ Department of Electrical and Computer Engineering, University of Alaska Fairbanks, Fairbanks, Alaska. \\ ${ }^{6}$ Huntington Consulting, Eagle River, Alaska. \\ ${ }^{7}$ Institute of Social and Economic Research, University of Alaska Anchorage, Anchorage, Alaska. \\ ${ }^{8}$ Department of Civil Engineering, University of Alaska Anchorage, Anchorage, Alaska.
}

Received: February 1, $2019 \quad$ Accepted in revised form: April 29, 2019

\begin{abstract}
In recent years, there has been increased recognition of the importance of a nexus approach to optimize food, energy, and water (FEW) security at regional and global scales. Remote communities in the Arctic and Subarctic regions in Alaska provide unique examples of closed and isolated systems, wherein the FEW nexus not only needs to be examined to lend resilience to these vulnerable communities but that could also serve as small-scale test beds for a wider and systematic understanding of the FEW nexus. In this short communication, looking at the FEW nexus in Cordova, Alaska, through an energy lens, we introduce an approach (referred to as the "MicroFEWs approach") that may assist remote communities in Alaska in making informed decisions regarding the use of renewable energy to increase FEW security. Our example uses the MicroFEWs approach to assess the impacts of increased renewable energy generation on FEW security in the community, more specifically to food security through potential changes to the community's fish processing industry. This approach can serve as a basis for investigating the FEW nexus in varying contexts and locales.
\end{abstract}

Keywords: Alaska; Arctic; food-energy-water; microgrids; remote communities; renewable energy

\section{Introduction}

The food-energy-water nexus in Alaska

A FOOD-ENERGY-WATER (FEW) nexus approach is useful for examining remote Alaska communities because it helps frame the usage of resources and trade-offs in a more holistic way, relating to resilience and sustainability of isolated, rural, and remote communities. With several hundred such communities in Alaska alone, this approach offers lessons for Alaska and beyond. Communities in these regions are populated with human settlements isolated from the contiguous infrastructure commonly available in other regions that

*Corresponding author: Alaska Center for Energy and Power, University of Alaska Fairbanks (UAF), P.O. Box 755910, Fairbanks, AK 99775. Phone: (907) 799-6724; Fax: (907) 786-7739; E-mail: erin.whitney@alaska.edu enhances FEW security and thus overall community wellbeing. In Fig. 1, for example, each dot represents a community in the pan-Arctic region isolated from the relevant continental or regional power grid, thereby leaving it responsible for maintaining its own islanded microgrid (Poelzer et al., 2016).

FEW security in this context includes four factors, which come originally from definitions of water security (e.g., Grey and Sadoff, 2007) and have been extended with some modification to energy and food (e.g.,FAO, 2008; Loring et al., 2013; Walch et al., 2018). The four factors are availability (how much of the resource exists in the locale of interest), accessibility (can people obtain what is available), suitability (is the resource what people want), and reliability (can people count on the resource). These factors include considerations of cost, nutritional content and cultural appropriateness (for food especially), and taste (for food and water), among others. Consideration of the FEW nexus, as described in this

(c) Erin Whitney, et al., 2019; Published by Mary Ann Liebert, Inc. This Open Access article is distributed under the terms of the Creative Commons Attribution Noncommercial License (http://creativecommons.org/licenses/by-nc/4.0/) which permits any noncommercial use, distribution, and reproduction in any medium, provided the original author(s) and the source are cited. 


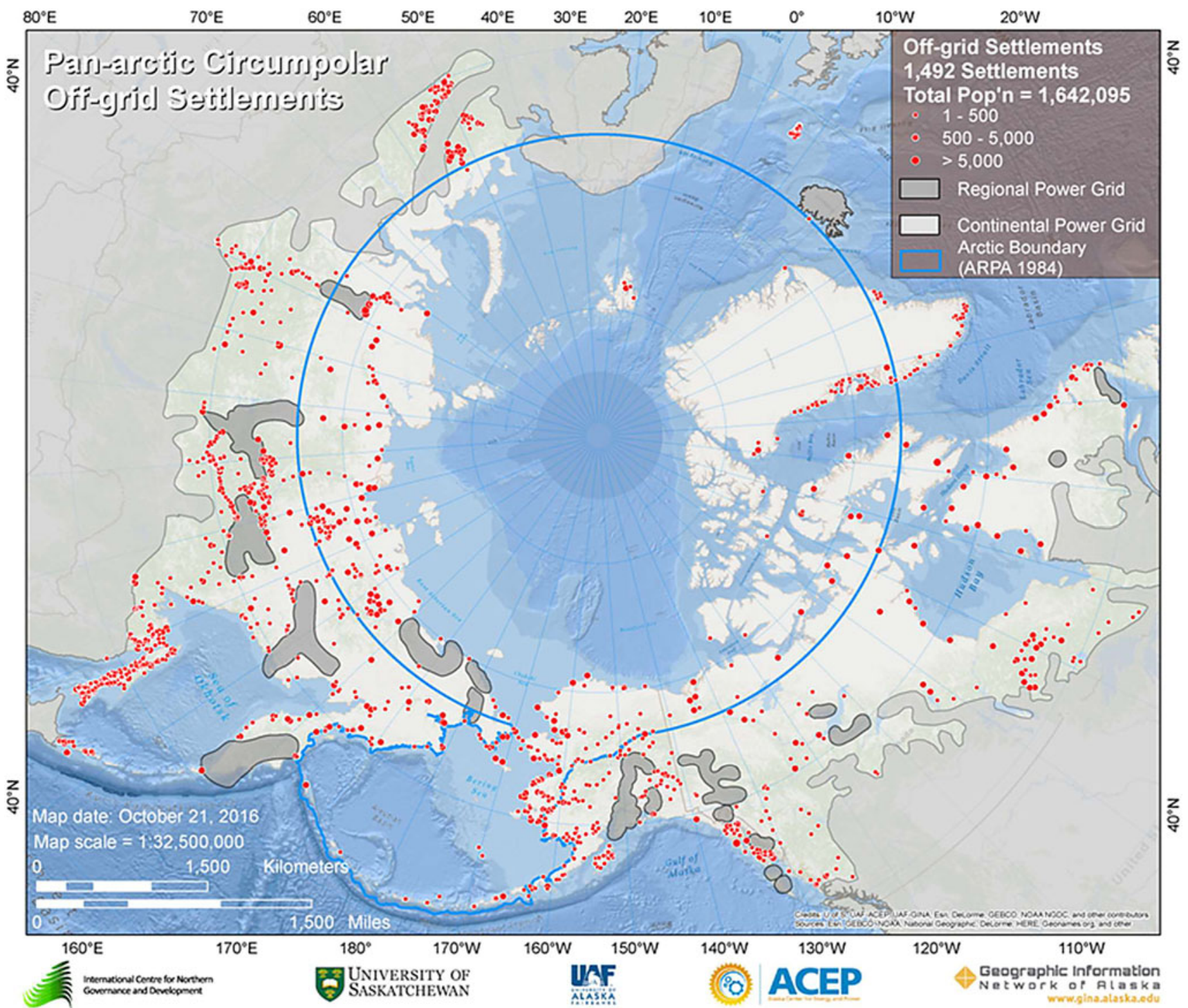

FIG. 1. Pan-Arctic circumpolar communities off the electrical grid system (Poelzer et al., 2016).

article, is intended to find opportunities for improvements that propagate through the nexus to yield extra benefits or, perhaps, cases wherein improvements in one aspect of FEW security may come at a cost in one or more of its other aspects. Extra benefits could include improvements in health, increased equity, environmental quality, access to modern energy, and more (Ringler et al., 2013).

Arctic and Subarctic communities are uniquely situated to serve as model systems for transformational FEW nexus research because they often lack FEW security while also constituting closed systems that can be studied for scalable approaches worldwide (White et al., 2007; Eichelberger, 2010; Alessa et al., 2011; Loring et al., 2013; Hossain et al., 2016). Exogenous inputs such as a community's food and fuel deliveries can be readily quantified in these isolated settlements due to the limited way shipments are received, as well as the limited routes by which supplies are delivered. Many such communities have only a single fuel depot, public power generating facility, water treatment facility, and grocery store. Information regarding endogenous resources, including subsistence foods, local water resources, and re- newable energy sources, is often available for inclusion into a community-wide model. Thus, small Arctic or Subarctic communities represent discrete instances of the FEW nexus and are ideally sized for thorough characterization.

\section{Climate change impacts on the FEW nexus in Alaska}

Climate impacts and changes in Alaska are also affecting FEW sectors and security, highlighting the need to understand baseline conditions for community planning efforts. High northern latitudes are warming much faster than more temperate zones. Alaska has warmed more than twice as rapidly as the rest of the United States, with statewide average annual air temperature having increased by $1.5^{\circ} \mathrm{C}$ and average winter temperature by $>3^{\circ} \mathrm{C}$ since the 1950 s (Walsh et al., 2014). A series of synthesis reports have documented and summarized a wide range of effects of recent and projected warming on the physical environment, ecosystems, and human activities (ACIA, 2004; Hovelsrud et al., 2011; AHDR, 2014; Chapin et al., 2014; Larsen et al., 2014). Although these effects of a warming climate are bound to 
have consequences separately on food, energy, and water, considerably less is known specifically about the effects on the FEW nexus. Unlike generations of the past (i.e., nomadic heritage), communities in rural Alaska today are immobile and highly dependent on local resources and infrastructure. Increases in population have exceeded sewer and water design capacities in some communities, changes in precipitation and erosion have threatened drinking water, and high energy costs have forced residents to make tough choices (Romanovsky et al., 2002; USACE, 2009; Brubaker et al., 2011a, 2011b; Overeem et al., 2011; Brinkman et al., 2014; Melvin et al., 2017; NSB, 2018). Understanding the FEW nexus and linkages now will help us to project and measure the impacts of these changes moving forward.

\section{Energy as a lens for the FEW nexus in Alaska}

We approach the problem of describing complex FEW relationships by designating energy as the initial lens through which we view the system. Energy is not only readily quantified but it is also linked to the provision of adequate food and water supplies in Arctic and Subarctic communities. More specifically, we propose that many of the primary linkages comprising the FEW nexus can be described by evaluating energy flows within FEW-related infrastructure. Thus, by examining the linkages of energy throughout a community's infrastructure, we seek to understand how energy affects products created by infrastructure (e.g., treated drinking water, greenhouse production), and understand those relationships to the products not directly created by that infrastructure (subsistence harvests, exogenous fuels, etc.). Then, linking those products to common measures of FEW security, we seek to better understand the FEW nexus as a system within a given community.

\section{Role of renewable energy linkages}

Although the energy linkages themselves serve as our portal into the FEW nexus, it is the introduction of renewable energy and its downstream impacts that provides the perturbations necessary to understand system dynamics. Whereas Arctic and Subarctic communities rely heavily on imported fossil fuels for diesel electric generation and oilfired heat, an increasing number of these remote communities are turning to hybrid generation systems that employ either firm (e.g., hydro and geothermal) or intermittent (e.g., solar photovoltaic and wind) renewable energy sources to supplement diesel electric generation. This trend toward increased reliance on renewable energy sources represents not only an opportunity for a fundamental study, but also an opportunity to develop research products with the immediate application of informing communities seeking to improve their FEW security.

By considering changes to a community's power generation system not only with respect to the loads they may support, but also with respect to the impact such loads may have upon the FEW nexus, a community can gain a better understanding of the downstream impacts of planning decisions. As such, the engineering aspects of our approach relate to the identification and characterization of loads in Arctic and Subarctic community infrastructure, along with the identification and characterization of renewable and fossil fuel sources.

\section{Methods}

\section{A community application: Cordova, Alaska}

In this short communication, looking at the FEW nexus in Cordova, Alaska, through an energy lens, we introduce an approach (referred to as the "MicroFEWs approach") that may assist remote communities in Alaska in making informed decisions regarding the use of renewable energy. Cordova (population 2,239 in 2010) is a maritime fishing community located in southcentral Alaska on the shores of Prince William Sound, near the mouth of the Copper River. The city generates its electric power from two hydroelectric facilities and a diesel electric generation plant. Most community residences are connected to the city water and wastewater treatment plants. According to the city administration, Cordova is a community of young families, and there is a growing interest in gardening, home food production, and access to clean and safe drinking water. Cordova is also a means to address the scalability of the MicroFEWs modeling process. Cordova is larger than most isolated Alaska communities and hosts a more robust industrial base (e.g., several commercial seafood processing facilities). However, it is also smaller than cities such as Kotzebue, Bethel, and Nome. Using Cordova affords the opportunity to either scale down to smaller villages or scale up to larger cities, whereas it may be difficult to start with a very small or a very large community and scale up or scale down to the opposite extreme. Hence, evaluating FEW interactions on this scale will provide insights into the broader applicability of the MicroFEWs approach to slightly larger as well as smaller remote communities.

\section{The MicroFEWs approach}

The goal of the MicroFEWs approach is to develop a datadriven and participative systems model to assist remote coldregion communities in making informed decisions regarding renewable power in the context of FEW security. In the following sections, we provide an example of how MicroFEWs can be used to predict the impacts of improvements to the renewable energy supply on food security in Cordova. This example describes the approach used to assess the impacts of increased renewable generation on FEW security in the community, more specifically to food security through potential changes to the community's fish processing industry. It should be noted that this is only one question that can be asked about the FEW nexus in Cordova, and that there are many, many more questions still to be posed and considered, including that of community well-being. For the purposes of this communication, we will also not elaborate on the metrics of FEW security in detail, which will be the focus of future publications.

The process begins with an extended period of community engagement activities focused on understanding the linkages and primary drivers of FEW security within the selected community. Existing FEW linkages in Cordova are presented in a simplified form in Fig. 2 to construct a generic and unweighted FEW framework configured to answer the question regarding the fish processing industry. In Fig. 2, FEW security within the community is represented in the black box labeled "Community." Other boxes represent end points of the system such as the components of the power utility, water utility, and activities contributing to food security. Energy 
FIG. 2. FEW framework for Cordova, Alaska, to evaluate relationships between hydroelectric power improvements and fish processing industry. Energy (red), water (blue), food or food product (green), and revenue (black) flows are illustrated by the colored arrows. FEW, food, energy, and water.

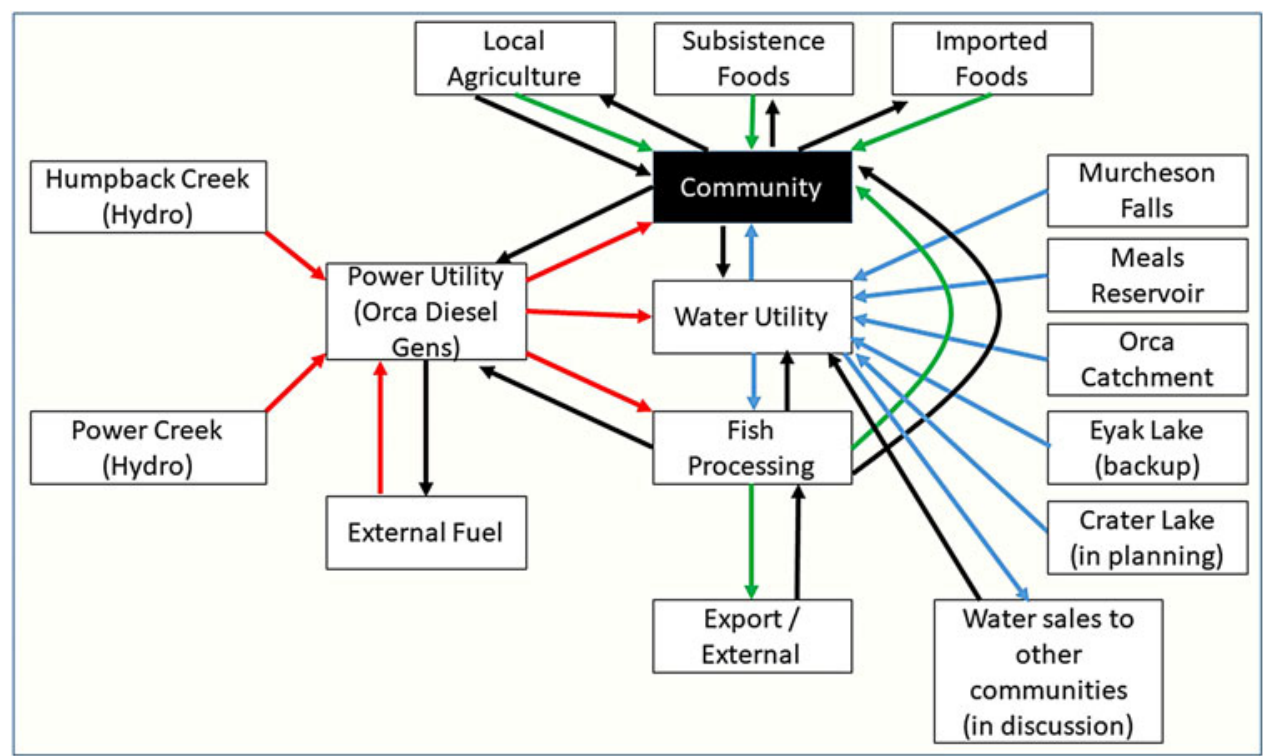

(red), water (blue), food or food products (green), and revenue (black) net flows are illustrated by the colored arrows. For example, the green arrow from fish processing to the community indicates that at least some fish from the processors go toward feeding the community. However, most fish consumed by the community are likely not through the processors, but rather from subsistence activities. Thus, the larger impact to food security from fish processing may be the dollars generated that can be used for food security. The blue line leading from the water utility to the fish processors indicates that the processors use a significant amount of water. Approximately $40-50 \%$ of metered water goes to the processors, with the highest amounts in July and August annually.

We note that the figure is a simplified version of existing complexity in the actual community system. For example, although some amount of energy is likely required to drive local agriculture, energy flow is not represented as a direct linkage, but instead captured as an element of energy security in the community box. A separate instance of the model fo- cused on elucidating the relationship between energy and local agriculture would have that specific linkage called out.

In addition, relative magnitudes of connections and impacts are not shown since our study is still ongoing and this figure is meant to show generic connections. Indeed, the relative weights of these connections vary depending on how one considers the system or how one is trying to change the system. As we work through the MicroFEWs process, we will better understand the strengths of these connections.

\section{Energy distribution model}

The energy distribution model (EDM) is intended to evaluate the direct linkages between the power sources and the FEW-related products associated with the community loads. A diagram of the EDM components relevant to the current example is provided in Fig. 3. To develop the model, the on-grid linkages between the power utility, its sources, and loads are evaluated at the Power Systems Integration
FIG. 3. FEW components and linkages (in black) evaluated in the energy distribution model. Energy (red), water (blue), food or food product (green), and revenue (black) flows are illustrated by the colored arrows.

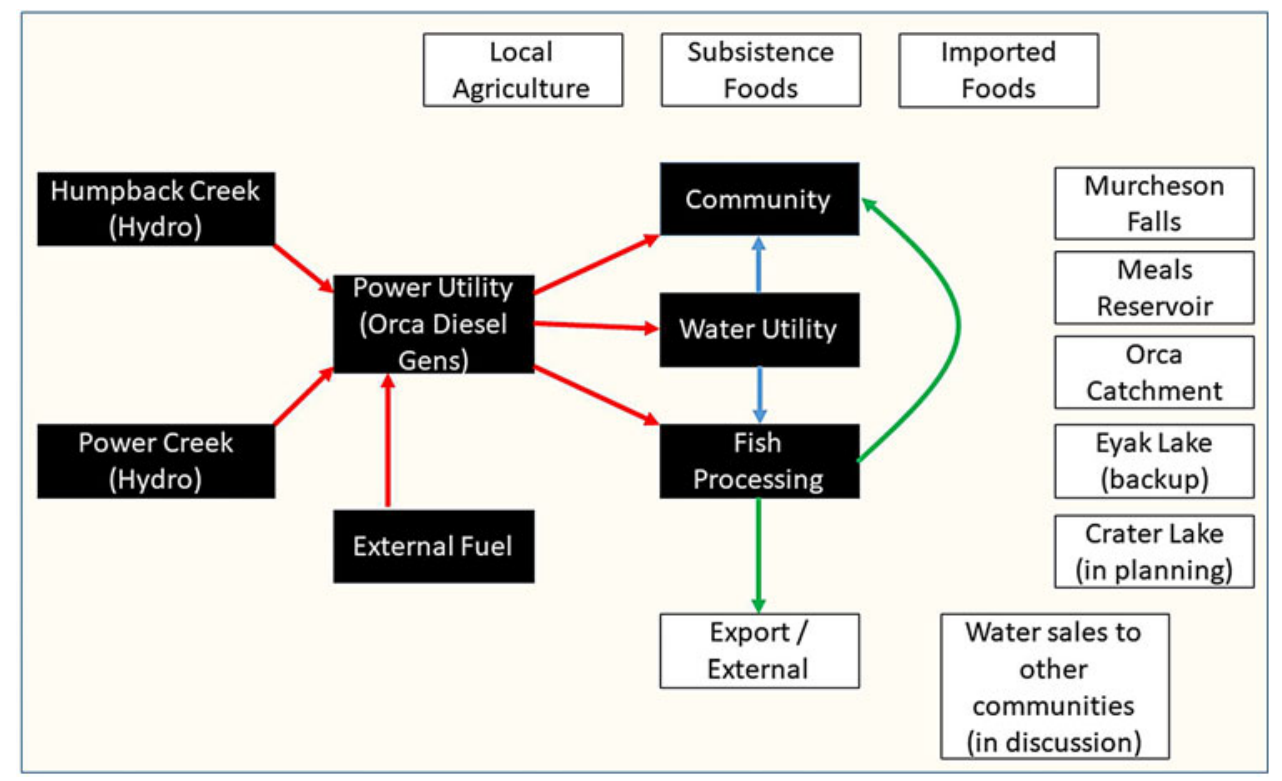


Laboratory at the University of Alaska Fairbanks, with prototype laboratory test setups of modular system loads (water reuse, powered septic systems, and crop boxes), and by metering in communities and existing deployed modular systems. This exercise is intended to evaluate changes to the quality and reliability of power brought about by the proposed addition of another renewable source. Next, a systems model such as Vensim (Ventana Systems, Inc.) is utilized to evaluate the impacts to the FEW-related products (e.g., water, processed fish) associated with the on-grid loads. Like the previous section, this example EDM is simplified and configured specifically to answer the question of renewable energy impacts upon the fish processing industry. Optimization algorithms are then chosen based on the stochastic nature of the linkages between the power sources and FEW-related products associated with the community loads. The selected optimization algorithm(s) are then used to determine the optimal amount of renewable energy to maximize FEW security while minimizing the negative impacts on FEW-related products.

As a simple quantitative example, we consider the impact on energy sourcing and availability for fish processing loads from the addition of a third $3 \mathrm{MW}$ Turgo hydroelectric turbine to the Power Creek generation facility in Cordova. Figure 4 shows a Vensim diagram illustrating linkages among hydroelectric power, diesel generation, and seafood processing plant loads in Cordova. Hourly (kWh) data sets were averaged from measured high-resolution time-series data provided by Cordova Electric Cooperative. They include generation from the Humpback Creek and Power Creek hydroelectric facilities, Orca diesel power plant, and fish processing loads taken from 15-min generation and load data spanning September 2012 to September 2013 and are available on the Alaska Energy Data Gateway (https://psi.alaska.edu/data). The fish processing loads are combined loads from the seafood processing plants during the summer fishing season, including fish plant building thermal loads, refrigeration and storage, fish processing, and lighting.

Using the connections in the Vensim diagram, we can create the hourly average energy generation at Power Creek hydroelectric facility with the currently installed two $3 \mathrm{MW}$ Turgo turbines during the fishing season from May to mid-

\section{Power Generation (Hydro and DEG's)}

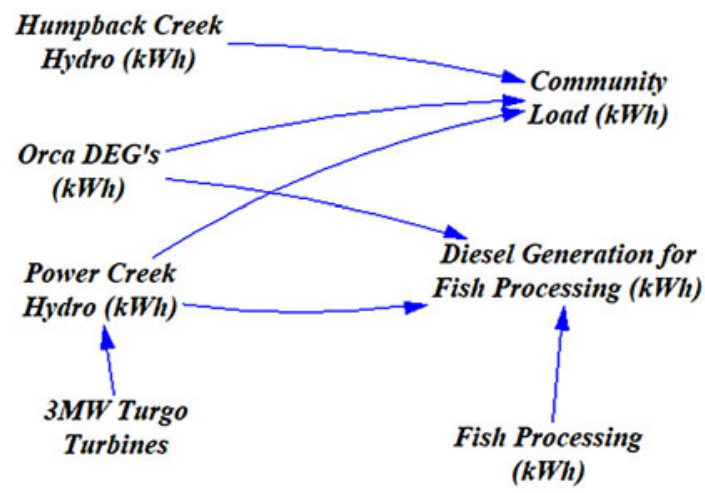

FIG. 4. A Vensim diagram illustrates linkages among hydroelectric power, diesel generation, and seafood processing plant loads in Cordova.
September, versus that for three turbines to offset diesel generation from the Orca diesel plant during the high demand fishing season, as shown in Fig. 5. The seafood processing plant load $(\mathrm{kWh})$ is the combined load from the three seafood processing plants in Cordova. From the figure, it is evident that adding an extra $3 \mathrm{MW}$ Turgo turbine will cover most of the energy demand from the seafood processing plants.

We can also consider the amount of displaced diesel from the addition of the extra $3 \mathrm{MW}$ Turgo turbine, as illustrated in Fig. 6. The dashed lines show the average hourly diesel generation before and after adding a $3 \mathrm{MW}$ Turgo turbine to the Power Creek hydroelectric facility. On average, diesel generation powering the seafood processing plants can be decreased by $\sim 50 \%$ from 2000 to $1091.8 \mathrm{kWh}$ by adding the additional Turgo turbine. This is a significant reduction in diesel consumption serving the fish processing load.

\section{Discussion}

\section{MicroFEWs synthesis}

Existing articles and studies provide a conceptual basis for the FEW nexus, but with few quantified examples like the EDM already mentioned, and little attempt to think across scales. The EDM, such as that described in the preceding section, predicts the impacts of power supply upon the FEWrelated products of the community's electric power load. However, those products (e.g., Fig. 3, water utility products and fish processing products) contribute to, but do not completely describe, community FEW security. The synthesis piece of the MicroFEWS approach allows for consideration of the EDM output in the context of the entire FEW framework. For example, water production and distribution to the community may be an important component of water security, but the raw flow rates of water are insufficient to describe community water security in the absence of other information. Cordova, for instance, experiences a high amount of annual precipitation such that the community considers itself to be water secure. Thus, doubling the production at the water utility would not necessarily double the level of water security. However, raw flow rates of water may impact energy security, as illustrated by the addition of a hydroelectric turbine and the resulting decrease in diesel consumption by seafood processing plants. Ultimately, the community and seafood processing plants can use this information to decide on preferred energy sources based on security metrics.

Although the EDM example provides a quantified illustration, it is not without its limits, the most significant of which are the data sources themselves. For this example in particular, we could not determine which specific electrical feeder serves the seafood processing plant loads, which we estimated as the difference between the data in the processing seasons and the off-season. Of course, this estimation does not account for potential increases in normal community load in the winter months and other loads on the feeder for the seafood processing plant. Therefore, even good electrical data do not provide exactly what is needed to accurately define specific interactions within the nexus.

\section{Conclusions}

In these examples for Cordova, water is abundant enough that there is no problem serving various needs. However, by 
(2) 3 MW Turgo Turbines at Power Creek

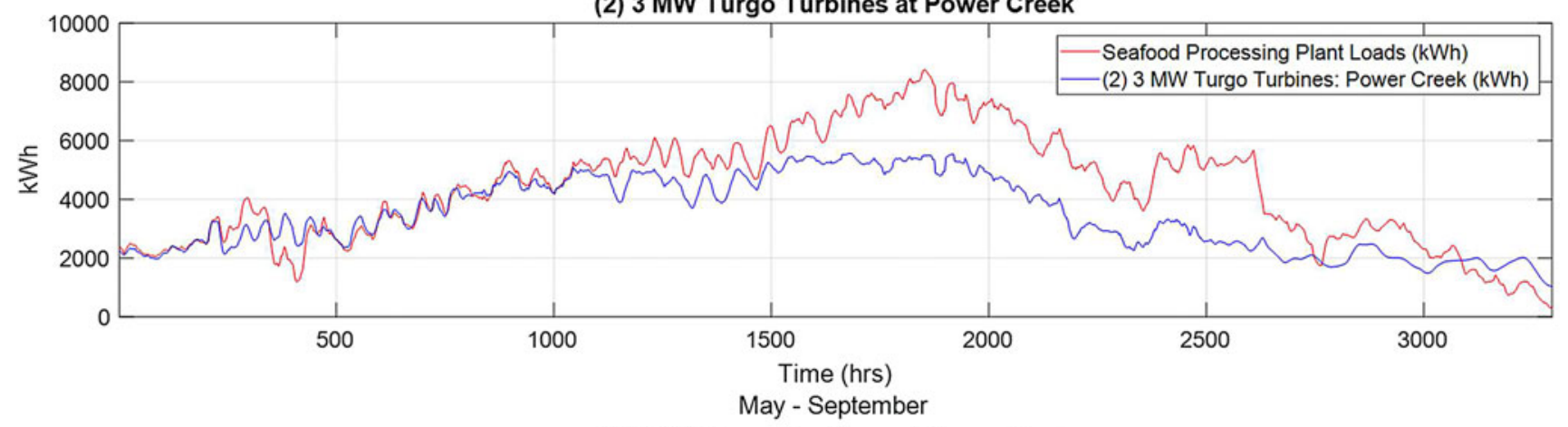

(3) 3 MW Turgo Turbines at Power Creek

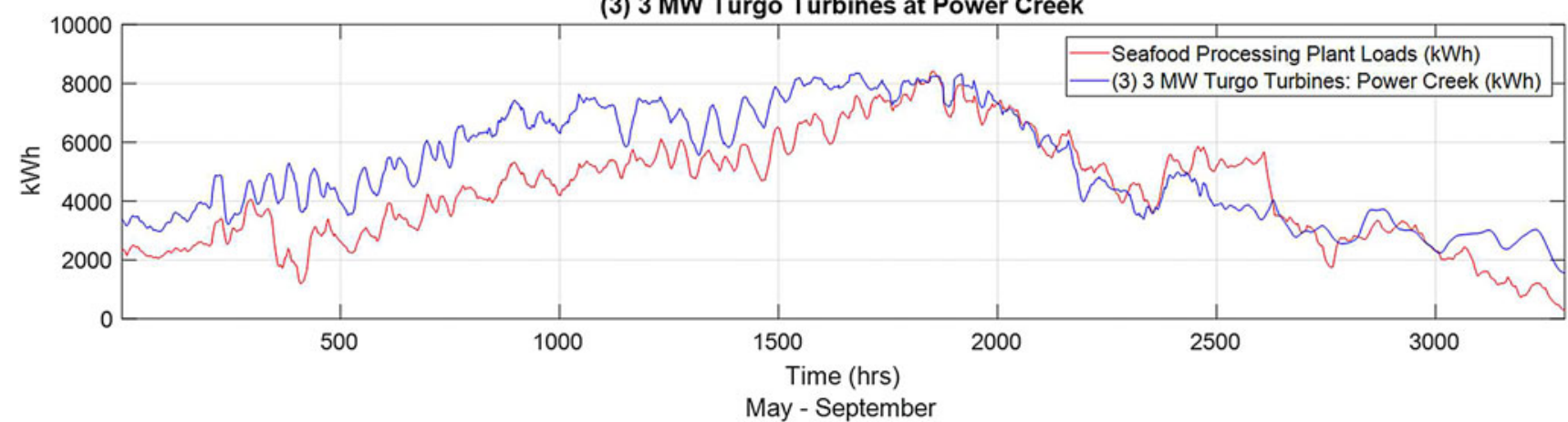

FIG. 5. Comparison of two (top graph) and three (bottom graph) $3 \mathrm{MW}$ Turgo turbines at Power Creek hydroelectric facility relative to seafood plant processing load. In both plots, the same seafood plant processing load is shown in red, and the turbine outputs are shown in blue.

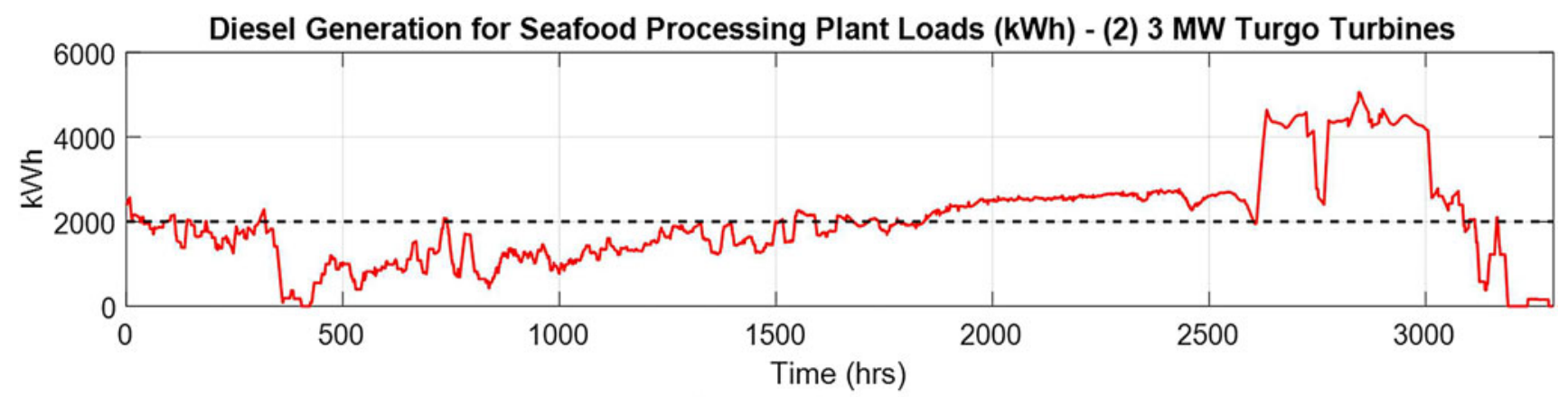

May 01 - September 15

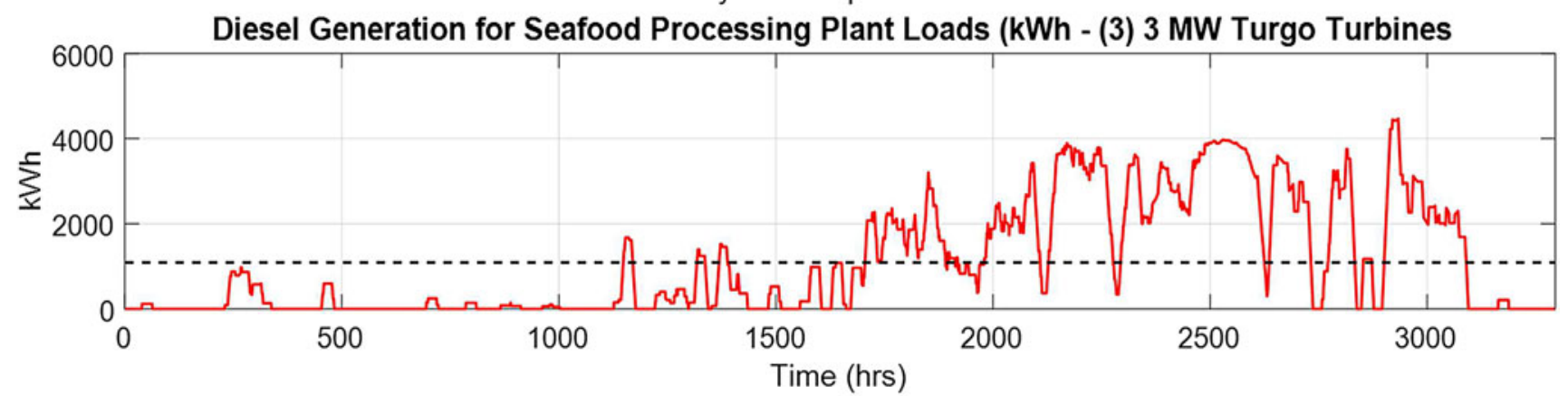

May 01 - September 15

FIG. 6. Diesel generation (kWh) with two (top graph) and three (bottom graph) 3 MW Turgo turbines at the Power Creek hydroelectric facility. Average diesel generation is indicated by the dashed lines $(2,000 \mathrm{kWh}$ with two turbines in the top graph and $1091.8 \mathrm{kWh}$ with three turbines in the bottom graph). 
considering the FEW nexus, we include real trade-offs and synergies that would not necessarily be apparent without this approach. Water can serve multiple purposes, turning hydroelectric turbines before flowing to the fish plant or municipal water system, but getting the most from the available water also requires consideration of energy demands, costs, and water quality to make optimal use of available resources and technologies.

In this relatively simple example, we have demonstrated the MicroFEWS approach to show how it can be applied to similar questions for Cordova and other isolated communities and yield more holistic insights by examining the FEW nexus. The FEW nexus approach in the Arctic is novel and goes beyond previous work often focused on individual components (Eichelberger, 2010; Alessa et al., 2011; Hossain et al., 2016). Loring et al. 2013 provided a framework for linking FEW and we take the next step by using the MicroFEWS approach to assess linkages by using a data-driven approach. Incorporating FEW interdependencies with this approach can lead to decisions that are more consistent with FEW security and community well-being. Ultimately, the answers to these questions have real impacts on resilience and sustainability in isolated and vulnerable communities. This approach can serve as a basis for investigating the FEW nexus in varying contexts and locales both in and outside Alaska.

\section{Acknowledgment}

Funding for this work was provided by the National Science Foundation, Award No. 1740075: INFEWS/T3: coupling infrastructure improvements to food-energy-water system dynamics in small cold region communities: MicroFEWs.

\section{Author Disclosure Statement}

No competing financial interests exist.

\section{References}

ACIA. (2004). Impacts of a warming Arctic: Arctic Climate Impact Assessment. Cambridge University Press, Cambridge, U.K. AHDR. (2014). Arctic Human Development Report: Regional Processes And Global Linkages. Copenhagen: Nordic Council of Ministers.

Alessa, L., Altaweel, M., Kliskey, A., Bone, C., Schnabel, W., and Stevenson, K. (2011). Alaska's freshwater resources: issues affecting local and international interests. JAWRA J. Am. Water Res. Assoc. 47, 143.

Brinkman, T., Maracle, K.B., Kelly, J., Vandyke, M., Firmin, A., and Springsteen, A. (2014). Impact of fuel costs on highlatitude subsistence activities. Ecol. Soc. 19, 9.

Brubaker, M., Bell, J., Berner, J., Black, M., Chavan, R., Smith, J., and Warren, J. (2011a). Climate Change in Noatak, Alaska. Anchorage, Alaska: Alaska Native Tribal Health Center.

Brubaker, M., Berner, J., Bell, J., and Warren, J. (2011b). Climate Change in Kivalina, Alaska: Strategies for Community Health. Alaska Native Tribal Health Consortium.

Chapin III, F.S., Trainor, S.F., Cochran, P., Huntington, H., Markon, C., McCammon, M., McGuire, A.D., and Serreze, M. (2014). Ch. 22: Alaska. In J. M. Melillo, R. Terese, and G. W. Yohe, Ed., Climate Change Impacts in the United States: The Third National Climate Assessment. Washington, D.C.: U.S. Global Change Research Program, p. 514.

Eichelberger, L.P. (2010). Living in utility scarcity: energy and water insecurity in northwest Alaska. Am. J. Public Health 100, 1010.
FAO. (2008). An introduction to the basic concepts of food security. FAO Food Security Programme. Available at: www .fao.org/3/a1936e/a1936e00.pdf (accessed May 29, 2019).

Grey, D., and Sadoff, C.W. (2007). Sink or Swim? Water security for growth and development. Water Policy 9, 545.

Hossain, Y., Loring, P.A., and Marsik, T. (2016). Defining energy security in the rural north-historical and contemporary perspectives from Alaska. Energy Res. Soc. Sci. 16, 89.

Hovelsrud, G.K., Poppel, B., van Oort, B., and Reist, J.D. (2011). Arctic societies, cultures, and peoples in a changing cryosphere. Ambio 40, 100.

Larsen, J. N., Anisimov, O.A., Constable, A., Hollowed, A.B., Maynard, N., Prestrud, P., Prowse, T.D., and Sto, J.M.R. (2014). Polar regions. In C. B. Field, V. R. Barros, D. J. Dokken, K. J. Mach, M. D. Mastrandrea, T. E. Bilir, M. Chatterjee, K. L. Ebi, Y. O. Estrada, R. C. Genova, B. Girma, E. S. Kissel, A. N. Levy, S. MacCracken, P. R. Mastrandrea, and L. L. White, Eds., Climate Change 2014: Impacts, Adaptation, and Vulnerability. Cambridge, United Kingdom and New York, NY: Cambridge University Press, p. 1567.

Loring, P.A., Gerlach, S.C., and Huntington, H.P. (2013). The new environmental security: linking food, water, and energy for integrative and diagnostic social-ecogical reearch. $J$. Agric. Food Syst. Community Dev. 3, 55.

Melvin, A.M., Larsen, P., Boehlert, B., Neumann, J. E., Chinowsky, P., Espinet, X., Martinich, J., Baumann, M. S., Rennels, L., Bothner, A., Nicolsky, D. J., and Marchenko, S. S. (2017). Climate change damages to Alaska public infrastructure and the economics of proactive adaptation. Proc. Natl. Acad. Sci. 114, E122.

NSB. (2018). North Slope Borough Comprehensive Plan: Public Review Draft. Barrow, Alaska: North Slope Borough. Overeem, I., Anderson, R.S., Wobus, C.W., Clow, G.D., Urban, F.E., and Matell, N. (2011). Seaice loss enhances wave action at the Arctic coast. Geophys. Res. Lett. 38, L17503.

Poelzer, G., Gjorv, G.H., Holdmann, G., Johnson, N., Magnusson, B. M., Sokka, L., Tsyiachiniouk, M., and Yu, S. (2016). Developing renewable energy in arctic and sub-arctic regions and communities. Available at: https://renewableenergy.usask.ca/ documents/FulbrightArcRenewableEnergy.pdf

Ringler, C., Bhaduri, A., and Lawford, R. (2013). The nexus across water, energy, land and food (WELF): Potential for improved resource use efficiency? Curr. Opin. Environ. Sustainability 5, 617.

Romanovsky, V., Burgess, M., Smith, S., Yoshikawa, K., and Brown, J. (2002). Permafrost temperature records: Indicators of climate change. Eos, Transactions American Geophysical Union 83, 589-594.

USACE. (2009). Alaska Baseline Erosion Assessment Study Findings and Technical Report. United States Army Corps of Engineers: Alaska District.

Walsh, J., Wuebbles, D., Hayhoe, K., Kossin, J., Kunkel, K., Stephens, G., Thorne, P., Vose, R., Wehner, M., Willis, J., Anderson, D., Doney, S., Feely, R., Hennon, P., Kharin, V., Knutson, T., Landerer, F., Lenton, T., Kennedy, J., and Somerville, R. (2014). Our Changing Climate. In J. M. Melillo, T. T. C. Richmond, and G. W. Yohe, Eds. Climate Change Impacts in the United States: The Third National Climate Assessment. Washington, DC: U.S. Global Change Research Program, p. 19. Walch, A., Bersamin, A., Philip, L., Johnson, R., and Tholl, M. (2018). A scoping review of traditional food security in Alaska. Int. J. Circumpolar Health. 77, 1419678.

White, D. M., Gerlach, S. C., Loring, P. A., and Tidwell, A. (2007). Food and water security in a changing arctic climate. Environ. Res. Lett. 2, 4. 